\title{
PREDICTING SPORTS FACILITY REVISIT INTENTIONS BASED ON EXPERIENCE AND MEDIATING EFFECTS OF PERCEIVED VALUE
}

\author{
SID TERASON \\ Kasetsart University, Faculty of Sports Science, Thailand \\ Mailing address: Sid Terason, Kasetsart University, Faculty of Sports Science, \\ 50 Ngam Wong Wan Road, Chatuchak, Bangkok 10900, Thailand, e-mail: fsssid@ku.ac.th
}

\begin{abstract}
Introduction. Several factors, such as program offerings, atmosphere and provided amenities, motivate repeat visits to sports destinations, with continued patronage most often associated with perceived value. Material and Methods. This study sought to determine the extent to which perceived value in sports facilities influenced revisit intentions, for which a path analysis model was used and a valid and reliable self-administered questionnaire was completed by 384 recreational sports facility visitors. Results. Visit experience and perceived value were found to influence revisit intentions, with nearly $50 \%$ of the direct effect being because of perceived value. Conclusions. The results of this study inform both academic practice and managerial decisions.
\end{abstract}

Key words: sports experience, perceived value, revisit intentions, sports facilities, Thailand

\section{Introduction}

Sports facilities concern the areas that are created and reserved for people to engage themselves in exercise and competition activities, such as a pool, gym and golf course, as well as any structures that facilitate and support their involvement in this kind of activities, such as a locker room, cafeteria, grandstand, athletic field, and scoreboard. A facility can either be a large arena with ground surfaces accommodating a diverse array of sports activities, or a small hall or room designed for a single sport. However, a sports facility can be converted into a theater, an auditorium, a convention center, a makeshift relief shelter, or other venues deviated from traditional sports functions such as health clubs, fitness center, park, golf field and recreation areas.

Several factors, including prices, program offerings, atmosphere and attractions, and amenities, such as parking, entertainment options, catering, staff services and transportation, have been found to motivate repeat visits to sports facilities $[1,2]$. As sports facility managers are held accountable for any business losses, they are expected to consider these factors in their day-to-day operations.

Managing and maintaining sports facilities can be a demanding and time-consuming undertaking [3]. Attracting people to first visit a facility takes considerable effort, but ensuring their return can be even more challenging. When a facility fails to attract repeat visitors, it faces the risk of losses and closure as has occurred in several sports venues worldwide [4, 5]. This is because it can no longer bear the financial burden under the no-clientele situation.

How a facility is managed by a sports manager greatly affects a user's perceptions of services and overall experience of the facility. Value of a facility as perceived by a user is shaped by the user experience which might or might not be in line with its actual value. This is typical of a service in general. Therefore, to ensure profitability and sustainability, sports facility management must design effective marketing activities to maintain and grow their customer base, which requires planning and operational principles that encourage client return [3]. However, client revisit intentions depend on many factors; therefore, if an organization can efficiently manage their sports and recreation facilities, they are more likely to make the best use of their facility and gain the most benefits [4].

\section{Literature review}

Marketing research has explored a wide range of service consumption concepts, such as service quality, perceived value, experience and promotions, with many studies having examined the associations between visit experiences, perceived value, brand loyalty, and purchase intentions [6, 7]. However, studies on the interrelatedness of these concepts have tended to find that the specific influences fluctuate over time [8]. Deriving a good experience from sports events or activities has also been found to depend on various factors, such as travel, accommodation, facilities and restaurants [9].

The relationship between experience and the perceived value of a product or service is associated with product experience and its costs and benefits. For example, Duman and Mattila [10] investigated the relationship between visiting experiences and perceived value in all-inclusive cruise vacations and confirmed that experience clearly influenced perceived value.

As customer loyalty has been recognized as vital to business success, customer loyalty antecedents have been widely researched for many years [11, 12]. For example, Oliver [13] identified cognition, emotion, conation and action as the four main stages of loyalty and suggested that consumers started to develop loyalty in each stage. The relationship between revisit intention and destination loyalty was explored in previous studies $[14,15$, 16]. They all suggested a significant relationship between revisit and loyalty.

Although perceived value and experience have been modeled in numerous studies to elucidate the hypothesized relationships, other than identifying the causal relations or simply 
examining the associations between these concepts, many questions on the actual relationship mechanisms remain unanswered. However, significant research has found experience to be a significant determinant of repeat visits to a service provider; that is, when a consumer is content with the product, they tend to visit a facility more frequently $[10,17,18]$.

Experience and perceived value have been widely discussed in relation to service; however, to date, no research has identified the causal tie between these two constructs [19]. Some studies advocating an experience-perceived value relationship have regarded perceived value and experience as antecedents for behavioral outcomes $[2,20]$; however, some earlier research $[21,22]$ suggested that experience directly influenced behavioral outcomes, with perceived value functioning only as a determinant.

Perceived value has been conceptualized in various ways. In an early study, Sheth et al. [23] identified five perceived value contexts: function, sociality, emotion, episteme, and situation. Then, Holbrook [24] described perceived value as an exchange-oriented experience and developed a perceived value typology that embodied three distinct polarities: orientation, activity and motivation. Mykletun et al. [9] later claimed that perceived value was a balance between perceived quality and sacrifice based on price, with sacrifice being either monetary or nonmonetary in nature, and was also related to how customers perceived and assessed the benefits they received.

In more recent studies, Moliner et al. [25] developed a perceived value model that integrated emotional, functional, and social value dimensions; Lee et al. [26] incorporated functionality, emotion, and overall value in a single construct; Cho and Yang [27] argued that perceived value was characterized by task-related and rational behavior, the elimination of hazards, the pursuit of pleasure and excitement, and social value; Gallarza et al. [28] saw perceived value as being associated with proposed efficiency, social value, service quality, play, aesthetics, and a combination of time and effort; and Williams et al. [29] concluded that perceived value was associated with utilitarian, affective, social, monetary, and novel attributes.

Originally, perceived value was not recognized as widely as customer satisfaction or service experience [30, 31] and was only examined as a crucial factor in the decision-making processes of consumer for physical products. More recent customer service studies, however, have tended to also consider psychological and social factors, such as hedonism, risk-taking and uncertainty [29].

It has been argued that perceived value is a strategic marketing consideration for producers and retailers in service settings [32] that significantly affects behavioral loyalty [21], whereby consumers would trade off between what they possessed and what they could offer. Therefore, perceived value was seen as a service-oriented construct that determined consumer intentions and consumption experiences [33].

The association between experience, perceived value and consumer revisit intentions has also been widely studied. Several studies established clear relationships between the various contributing factors and effects and concluded that perceived value significantly contributed to retail and service and hospitality industry growth [34, 35]. Hutchinson et al. [33] claimed that perceived value encompassed both consumer intentions and consumption experience.

Given this background, this study analyzed how experience influenced revisit intentions and the possible impact of perceived value as a mediator to expand existing knowledge and provide insights into this specific variable. In particular, this study sought to determine the extent to which perceived value influenced sports facility revisit intentions, for which a path analysis model was developed to predict sports facility visitor revisit intentions based on experience and determine the mediating effects of perceived value constructs.

To direct the research, based on the literature review, the following hypotheses were proposed:

$\mathrm{Hl}$ : Visit experiences exert a predictive effect on revisit intentions.

H2: Visit experiences exert a predictive effect on social, economic and emotional values.

H3: Social, economic and emotional values exert a predictive effect on revisit intention.

$\mathrm{H} 4$ : Social, economic and emotional values exert a mediating effect on the relationship between prior visiting experiences and revisit intentions.

\section{Material and Methods}

\section{Participants}

Data were collected using purposive sampling from 384 patrons (out-of-area tourists) at some selected recreational sports establishments in Thailand, such as golf courses, swimming pools, fitness centers and football fields. The inclusion criteria were participants that had visited these diverse sports facilities at least once a week in the last two months, with the number of participants determined based on a 95\% confidence level, a standard deviation of 2, and a maximum error of 0.2 [36].

Participants were asked to electronically respond to a set of questions using their cell phones so that the answers could be automatically tallied and anonymity and confidentiality retained. All participants voluntarily participated and received no monetary rewards. Of the 397 initial responses, 384 (96\%) were satisfactorily completed.

As shown in Table 1 , most participants were males with age ranging from 35 to 66 years $(\mathrm{M}=56.87$ years, $\mathrm{SD}=4.59)$, with over half having attended university. The average monthly

Table 1. Participant characteristics.

\begin{tabular}{|l|c|c|}
\hline Characteristics & $n$ & $\%$ \\
\hline Gender & & \\
\hline Male & 337 & 87.8 \\
\hline Female & 47 & 12.2 \\
\hline Highest educational level completed & & \\
\hline High school & 60 & 15.6 \\
\hline Undergraduate school & 122 & 31.8 \\
\hline Graduate school & 124 & 32.3 \\
\hline Vocational school & 78 & 20.3 \\
\hline Favorite facility location & & \\
\hline Central Thailand & 145 & 37.7 \\
\hline Northern Thailand & 121 & 31.5 \\
\hline Eastern Thailand & 46 & 12.0 \\
\hline Others & 72 & 18.8 \\
\hline & $M$ & $S D$ \\
\hline Age (years) & 56.87 & 4.59 \\
\hline Monthly income (\$) & 2,430 & 432.21 \\
\hline Number of monthly visits & 3.12 & 0.21 \\
\hline
\end{tabular}


income of the sample was $\$ 2,430$ ( $\mathrm{SD}=432.21$ ). Over one-third (38\%) rated sports facilities in central Thailand as their favorite facilities, with most visiting their facilities about thrice (SD = 0.43 ) in the last month (prior to the survey).

\section{Instruments}

The Likert-type scales for measuring the variables under investigation were developed based on the steps recommended in DeVellis [37] and Netemeyer et al. [38]. Supported by the comprehensive literature review $[39,40]$ and an extensive interview with a panel of sports business professionals and sports facility managers, a set of questionnaire items was developed.

The first part of the survey addressed the constructs under study, with each involving three to four statements; each statement is accompanied by a five-point Likert-type agreement scale from 1 (strongly disagree) to 5 (strongly agree). The final part of the questionnaire involved personal data, such as gender, education, favorite location, age, income and visit frequency.

\section{Data Analysis}

This study was focused on the two variables that predicted visitor intentions to revisit certain sports facilities, with the predictors being configured into the hypothesized model shown in Figure 1. A statistical mediation analysis was conducted using IBM SPSS AMOS 24 [41] to determine if perceived value mediated the relationship between visit experience and revisit intention. As suggested by Anderson and Gerbing [42], the analysis was performed in two stages. First, measurement model analysis was conducted, in which the measurement qualities were evaluated using confirmatory factor analysis. Second, structural model analysis was conducted, in which a structural equation modeling (SEM) was executed to assess the hypothesized relationships.

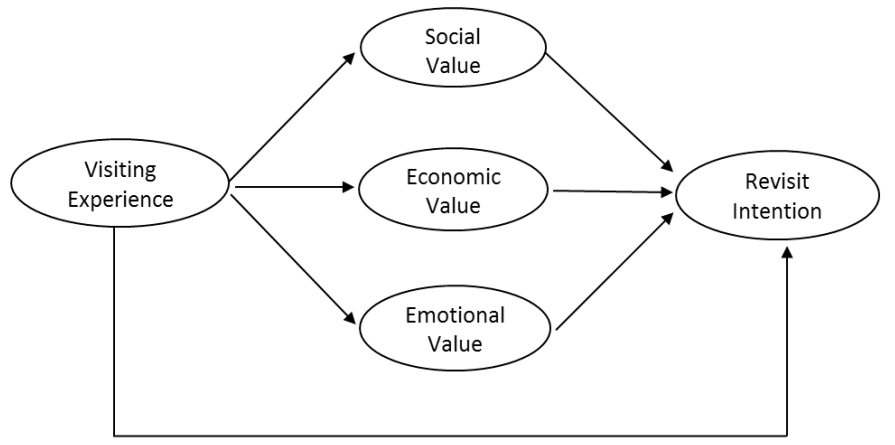

Figure 1. Conceptual framework

\section{Results}

To gage if the constructed measures had content validity, the initial questionnaire items were assessed by three industry experts and academics in this area, with their respective responses used to calculate the content validity ratio (CVR). Corrections and adjustments based on their recommendations were then made to improve clarity and accuracy until the CVR reached the minimum criterion of 0.56 [43]. The final question items are shown in Table 2.

Because of the reliance of this study on SEM, construct reliability (CR) was used to assess the internal consistency of measures. The results shown in Table 2 indicate that the CR coefficients were greater than 0.7 , which were deemed acceptable [44]. In addition to CR, the alpha coefficient $(\alpha)$ [45] was applied to assess reliability [44], which ranged from 0.70 to
0.85 , as shown in Table 2 , indicating that there were no reliability problems [46].

SEM was applied to address convergent validity and discriminant validity. The variables posited to measure the same construct show convergent validity if their intercorrelations are noticeable in magnitude [47]. A high CR level was obtained, which indicated that there was internal consistency and that the indicators all consistently represented the same construct. Therefore, the scales were considered to have acceptable validity.

Discriminant validity is warranted if the inter-measure correlations measuring the different constructs are not excessively high [47]. To achieve this, a test was implemented by comparing the average variance extracted (AVE) and the squared correlation coefficient [48]. The AVE for all constructs ranged from 0.66 to 0.81 . Table 2 shows that the AVE estimates were greater than 0.5 [44, 48], the CR coefficients were greater than 0.7 , and the factor loadings were over 0.5 [44].

The proposed model was subjected to a principal axis factor analysis with a promax rotation, from which it was found that the yielded pattern coefficients relating the factors with the items were robust, ranging from 0.56 to 0.76 . The fit indices for the model revealed a statistically significant fit: $\mathrm{GFI}=0.98$, $\mathrm{IFI}=0.96, \mathrm{TLI}=0.96, \mathrm{CFI}=0.97$, and RMSEA $=0.03[44]$.

Table 2. Factor loadings, average variance extracted and composite reliability.

\begin{tabular}{|c|c|}
\hline Item & $\Lambda$ \\
\hline Construct: Experience (AVE $=0.72, C R=0.62, a=0.85)$ & \\
\hline I had an overall good experience on my visit. & 0.77 \\
\hline The facilities were clean. & 0.72 \\
\hline The travel distance was not a problem for my visit. & 0.77 \\
\hline The staff were courteous. & 0.71 \\
\hline Construct: Social Value (AVE $=0.77, C R=0.56, a=0.79)$ & \\
\hline The visit enables me to expand my social network. & 0.69 \\
\hline The visit causes other people to admire me. & 0.79 \\
\hline The experience has made me more sociable. & 0.77 \\
\hline Construct: Economic Value (AVE $=0.76, C R=0.57, \alpha=0.70)$ & \\
\hline The facilities offer reasonable prices. & 0.71 \\
\hline The prices for incremental services were acceptable. & 0.87 \\
\hline The visit represented monetary value. & 0.81 \\
\hline Construct: Emotional Value (AVE $=0.70, C R=0.58, \alpha=0.72$ ) & \\
\hline The visit gives a sense of wellness. & 0.87 \\
\hline I find the visit very pleasant. & 0.87 \\
\hline The visit arouses my interest or enthusiasm. & 0.84 \\
\hline Construct: Revisit Intention (AVE $=0.79, C R=0.64, \alpha=0.71$ ) & \\
\hline I plan to come back some time. & 0.80 \\
\hline I plan to bring friends or family along next time. & 0.81 \\
\hline The facilities are worth a revisit. & 0.82 \\
\hline
\end{tabular}

Factor loadings were significant. AVE = average variance extracted; $\mathrm{CR}=$ construct reliability; $\alpha=$ internal consistency reliability; $\lambda=$ factor loading. 
Overall, based on the goodness of fit, composite reliability, and construct validity present, the model was found to be suitable for further testing using SEM. As the maximum likelihood estimation method assumes multivariate normality [47], all the univariate distributions were examined to assess normality. As no skew index was greater than 0.3 and no kurtosis index was greater than 10 [49], there was no departure from normality found.

Before conducting the mediation analysis, the assumptions were checked and met; that is, it was ascertained that the relationships between experience and revisit intentions were linear (determined using a matrix scatterplot) and that the error was normally distributed and uncorrelated with experience (determined using scatterplots for each regression). The variables had the correct causal ordering, and as all data were simultaneously collected, there was no reverse causality.

Table 3 presents a correlation matrix with the variable means and standard deviations. All zero-order correlations were significant and ranged from 0.65 (for the two variables: experiences and social value) to 0.88 (for the two variables: economic value and emotional value). The lowest mean was 3.65 and the highest 4.05, and the standard deviations ranged from 0.14 to 1.34 .

Table 3. Factor loadings, average variance extracted and composite reliability.

\begin{tabular}{|l|c|c|c|c|c|c|c|}
\hline Measure & $M$ & $S D$ & 1 & 2 & 3 & 4 & 5 \\
\hline 1. EX & 3.65 & 1.34 & - & & & & \\
\hline 2. SV & 4.05 & 0.14 & 0.65 & - & & & \\
\hline 3. EV & 3.05 & 0.22 & 0.75 & 0.76 & - & & \\
\hline 4. MV & 4.01 & 1.01 & 0.77 & 0.61 & 0.88 & - & \\
\hline 5. RI & 3.99 & 1.09 & 0.71 & 0.69 & 0.85 & 0.81 & - \\
\hline
\end{tabular}

$\mathrm{EX}=$ experience; $\mathrm{SV}=$ social value; $\mathrm{EV}=$ economic value; $\mathrm{MV}=$ emotional value; $\mathrm{RI}=$ revisit intention. All coefficients were significant at $p<0.01$.

Baron and Kenny [50] claimed that a mediating effect existed when there was a direct relationship between the independent variable (IV) and the dependent variable (DV), a direct relationship between the IV and the mediator variable, or a direct relationship between the mediator variable and the DV. Full mediation exists when the IV is not related to the DV and the mediator is controlled for, and partial mediation exists when they are related and the mediator is controlled for. Table 4 shows the analytical results for two unmediated models and the one mediated model. The first model was tested to assess the direct effect of the predictor variable (experience) on outcome variable (revisit intention), and the subsequent models assessed the direct effect on mediators (perceived value), the effect of mediators on outcome variable, and the combined effect of experience and perceived value in predicting revisit intentions.

All hypotheses were supported. The predictive effect of experience on revisit intention was found to be significant $(F(1$, $382)=5.75, p=0.017$ ), with experience explaining $58 \%$ of the variances in revisit intention. A one standard deviation increase in experience could be expected to increase revisit intentions by 0.95 standard deviations $(\beta=0.95, p=0.011)$.

The analysis also indicated that experience significantly predicted the three perceived values, whereas perceived value in turn was found to affect revisit intentions. Therefore, it was concluded that perceived value exerted full mediating effects on the relationship between experience and revisit intentions. For example, experience indirectly affected revisit intentions through social value $(\beta=0.63, p=0.012)$. Figure 2 gives a schematic representation of the entire path structure for the models along with their $\beta$ coefficients.

As detailed in Table 4, significant direct relations were warranted, the mediation path was significant, and experience was reduced in absolute size after controlling for perceived value but remained not equal to zero, which confirmed that partial mediation existed. However, if the direct relationship was not significant upon the addition of a mediator, it could be inferred that full mediation was warranted [51].

The paths from experience to the mediator and from the mediator to revisit intentions were mostly consistent with the proposed hypotheses. In other words, there was evidence that perceived value significantly served as a mediator, that is, a better experience led to a greater value perception, which in turn led to a higher level of revisit intentions. From the estimated indirect effects, it was deduced that perceived value was a legitimate mediator because the $95 \%$ confidence interval did not contain zero (see Table 4 ).

Table 3. Factor loadings, average variance extracted and composite reliability.

\begin{tabular}{|l|c|c|c|c|c|c|}
\hline \multicolumn{1}{|c|}{ Model } & $B$ & $S E B$ & $95 \% \mathrm{Cl}$ & $\beta$ & $p$ & $R^{2}$ \\
\hline $\mathrm{EX} \rightarrow \mathrm{RI}$ & 0.76 & 0.20 & {$[0.32,1.99]$} & 0.95 & 0.011 & 0.58 \\
\hline $\mathrm{EX} \rightarrow \mathrm{SV}$ & 0.66 & 0.25 & {$[0.02,0.94]$} & 0.76 & 0.004 & 0.45 \\
\hline $\mathrm{SV} \rightarrow \mathrm{RI}$ & 0.72 & 0.16 & {$[0.01,0.88]$} & 0.83 & 0.028 & 0.53 \\
\hline $\mathrm{EX} \rightarrow \mathrm{SV} \rightarrow \mathrm{RI}$ & 0.45 & 0.16 & {$[0.03,1.98]$} & 0.63 & 0.012 & 0.75 \\
\hline${ }^{*} \mathrm{EX} \rightarrow \mathrm{RI}$ & 0.47 & 0.56 & {$[0.19,0.33]$} & 0.45 & 0.011 & 0.61 \\
\hline $\mathrm{EX} \rightarrow \mathrm{EV}$ & 0.53 & 0.15 & {$[0.16,1.07]$} & 0.74 & 0.001 & 0.63 \\
\hline $\mathrm{EV} \rightarrow \mathrm{RI}$ & 0.61 & 0.12 & {$[1.02,1.94]$} & 0.80 & 0.003 & 0.77 \\
\hline $\mathrm{EX} \rightarrow \mathrm{EV} \rightarrow \mathrm{RI}$ & 0.74 & 0.13 & {$[1.01,1.93]$} & 0.59 & 0.002 & 0.83 \\
\hline${ }^{*} \mathrm{EX} \rightarrow \mathrm{RI}$ & 0.43 & 0.31 & {$[0.11,1.08]$} & 0.55 & 0.012 & 0.55 \\
\hline $\mathrm{EX} \rightarrow \mathrm{MV}$ & 0.77 & 0.09 & {$[0.37,1.94]$} & 0.73 & 0.001 & 0.66 \\
\hline $\mathrm{MV} \rightarrow \mathrm{RI}$ & 0.67 & 0.18 & {$[0.61,2.23]$} & 0.71 & 0.021 & 0.61 \\
\hline $\mathrm{EX} \rightarrow \mathrm{MV} \rightarrow \mathrm{RI}$ & 0.60 & 0.15 & {$[0.44,1.94]$} & 0.51 & 0.010 & 0.70 \\
\hline${ }^{*} \mathrm{EX} \rightarrow \mathrm{RI}$ & 0.66 & 0.09 & {$[0.01,1.22]$} & 0.32 & 0.017 & 0.52 \\
\hline
\end{tabular}

* - indicates the mediated direct effect.

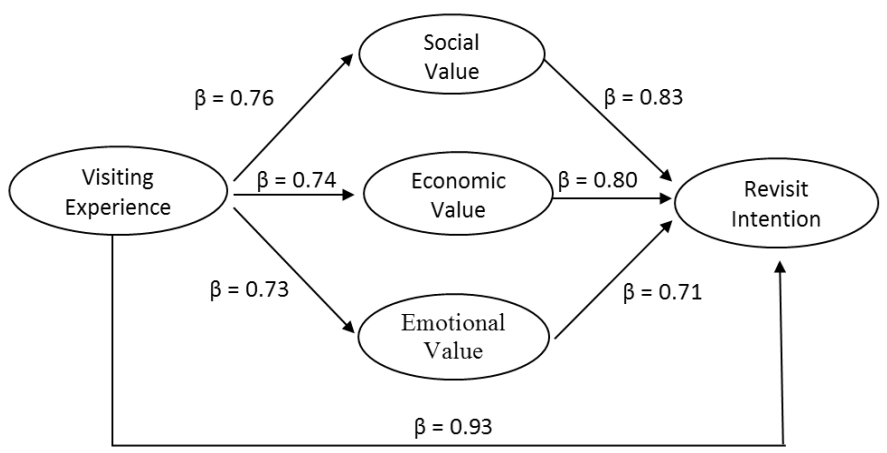

Statistics are standardized regression coefficients. All coefficients are significant at $\mathrm{p}<.05$

Figure 2. Path analysis predicting revisit intentions 


\section{Discussion}

Overall, the findings were consistent with previous service marketing research $[39,40]$ that established that customer experience significantly influenced customer revisit intentions. Experience was also found to positively influence perceived value, as also concluded in Cronin et al. [21]. However, the current study proposed a perspective for the role of the mediator (perceived value) different from the traditional experience-revisit models in explaining how experience influenced revisit intention as it was expected that the mechanism between experience and revisit intention would be revealed.

As the aim was to provide evidence on whether perceived value exerted a mediation effect on the relationship between visit experience and revisit intention, the aforementioned information enhanced the understanding of the relationship between experience and revisit plans. Therefore, these findings contribute to previous marketing studies on customer experience, repurchase and satisfaction as they were able to demonstrate the contribution of perceived value as a mediating variable in triggering the mechanism in this association.

This study was grounded in sports tourism services as the analysis was focused on how experience influenced tourist loyalty and how perceived value mediated this relationship. These findings expand the body of knowledge of perceived value in sports tourism and provide a better understanding of the interrelationships between the facility factors affecting revisit intentions. The effects of experience on revisit intentions have long been investigated [50]; however, the role of perceived value as an intervening variable between visit experience and revisit intentions was the sole focus of this inquiry and particularly the way visit experiences affected value perception. It was observed that there was an increase in the sense of loyalty when perceived value was positive, which was in line with the findings in Hutchinson et al. [33] and He and Song [22].

However, there were some limitations in the research design. To test the relationship, a one-shot study rather than a longitudinal study was used, which made determining long-term effects difficult. A larger sample would also have allowed testing to increase the power of the test. The study only included recreational golfers, who had possibly been lured to the clubs by different incentives, such as specific marketing promotional programs, which means their responses might not have fully reflected their prior service experiences.

The large effects observed in the study indicated that enhancing first visit experiences using value strategies could heighten the chance of subsequent visits. Management could also consider providing experiential offerings, such as travel-related convenience and accommodation to improve customer patronage.

The findings of this study shed light on the importance of the affective dimension when designing marketing strategies to improve customer revisit intentions, as described in Mazodier and Merunka [53]. As consumers differently perceive value in different cultures [11], future research could consider exploring the perceptions of customers for the same offered experience in different countries.

In addition to offering an insight into the impact of perceived value on the relationship between visit experience and revisit intention, the study findings also raised several managerial implications for the promotion of sports tourism industry products. This study gives a novel perspective on the behavior of sports consumers, which could contribute to targeted market- ing strategies for building customer loyalty, gaining competitive advantage and revitalizing sports industries.

As the results of this study provide insight into the association between experience and revisit intentions and highlight the effect of perceived value, it opens a new path for further inquiry, to examine the other phases of product loyalty, as proposed by Oliver [13]. Most previous work has concerned perceived value constructs without conceptualizing the dimensions. As this study drew from a sample of previous visitors, future researchers could target participants from different sports settings offering similar services. Alternatively, researchers could explore different value dimensions not studied in the current research.

Studies on sports experiences, perceived value and revisit intentions suggest that visit experiences significantly affect revisit intentions; therefore, a model was proposed to test and validate the likely mediator in this relationship. The conceptual framework was then proven using a mediation analysis on the data collected from sports players, with the results revealing the association between golfing experience and revisit intentions through perceived value.

\section{Conclusions}

Sports businesses seek to attract long-term visitors and specifically repeat visits; therefore, understanding the mechanism through which experience affects revisit intentions can greatly assist sports business managers. This study sought to determine the extent to which experience predicted revisit intention for a sports venue under the assumption that perceived value was the intervening construct. It was found that all proposed mediators partially mediated the relationship. Therefore, it is important that the social, economic and emotional perceived values that attract visitors and influence their future intentions be identified to improve the prospect of repeat visits.

\section{References}

1. Osti L., Disegna M., Brida J.G. (2012). Repeat visits and intentions to revisit a sporting event and its nearby destinations. Journal of Vacation Marketing 18(1), 31-42. DOI: $10.1177 / 1356766711428803$

2. Sabiote-Ortiz C.M., Frías-Jamilena D.M., Castañeda-García J.A. (2016). Overall perceived value of a tourism service delivered via different media. Journal of Travel Research 55(1), 34-51. DOI: 10.1177/0047287514535844

3. Fried G., Kastel M. (2021). Managing sport facilities (4th ed.). Human Kinetics.

4. Asefi A., Nosrati G.A. (2020). The spatial justice in the distribution of built outdoor sports facilities. Journal of Facilities Management 18(2), 159-178. DOI: 10.1108/JFM-092019-0051

5. Pricop A.D., Pelin R., Florescu O., Mezei M.D. (2020). Diversification of sports activities in technical higher education by improving sports facilities. Physical Education, Sport $\mathcal{E}$ Kinetotherapy Journal 59(3), 202-215. DOI: 10.35189/dpeskj.2020.59.3.1

6. Garcia-Fernandez J., Galvez-Ruiz P., Velez-Colon L., Bernal-Garcia A. (2016). Service convenience, perceived value, satisfaction, and loyalty: A study of consumers from lowcost fitness centers in Spain. Journal of Physical Education and Sport 16(1), 1146-1152. DOI: 10.1016/j.smr.2017.07.003

7. Zeithaml V.A., Berry L.L., Parasuraman A. (1996). The behavioral consequences of service quality. Journal of Marketing 60(2), 31-46. DOI: 10.1177/002224299606000203 
8. Johnson M.D., Herrmann A., Huber F. (2006). The evolution of loyalty intentions. Journal of Marketing 70(2), 122132. DOI: $10.1509 / j m k g .70 .2 .122$

9. Mykletun R.J., Crotts J C., Mykletun A. (2001). Positioning an island destination in the peripheral area of the Baltics: A flexible approach to market segmentation. Tourism Management 22(5), 493-500. DOI: 10.1016/S02615177(01)00004-8

10. Duman T., Mattila A.S. (2005). The role of affective factors on perceived cruise vacation value. Tourism Management 26(3), 311-323. DOI: 10.1016/j.tourman.2003.11.014

11. Ha Y.W., Park M.C. (2013). Antecedents of customer satisfaction and customer loyalty for emerging devices in the initial market of Korea: An equity framework. Psychology and Marketing 30(8), 676-689. DOI: 10.1002/mar.20637

12. McMullan R., Gilmore A. (2008). Customer loyalty: An empirical study. European Journal of Marketing 42(9/10), 1084-1094. DOI: 10.1108/03090560810891154

13. Oliver R.L. (1999). Whence consumer loyalty? Journal of Marketing 63, 33-44. DOI: 10.1177/00222429990634s105

14. Huang S., Hsu C.H. (2009). Effects of travel motivation, past experience, perceived constraint, and attitude on revisit intention. Journal of Travel Research 48(1), 29-44. DOI: $10.1177 / 0047287508328793$

15. Kozak M. (2001). Repeaters' behavior at two distinct destinations. Annals of Tourism Research 28(3), 784-807. DOI: 10.1016/S0160-7383(00)00078-5

16. San Martín H., Del Bosque I.A.R. (2008). Exploring the cognitive-affective nature of destination image and the role of psychological factors in its formation. Tourism Management 29(2), 263-277. DOI: 10.1016/j.tourman.2007.03.012

17. Li X.R., Petrick J.F. (2008). Examining the antecedents of brand loyalty from an investment model perspective. Journal of Travel Research 47(1), 25-34. DOI: $10.1177 / 0047287507312409$

18. Yoon Y., Uysal M. (2005). An examination of the effects of motivation and satisfaction on destination loyalty: A structural model. Tourism Management 26(1), 45-56. DOI: 10.1016/j.tourman.2003.08.016

19. Akinci S., Kiymalioglu A., Inana E.A. (2015). How golf players' satisfaction from golf experience predicts their loyalty intentions? Mediating role of perceived value. International Journal of Culture, Tourism and Hospitality Research 9(2), 117-132. DOI: 10.1108/IJCTHR-04-2014-0033

20. Lee, J., Kao, H., Yang, H. (2014). Service Innovation and Smart Analytics for Industry 4.0 and Big Data Environment. Procedia CIRP 16, 2014, 3-8.

21. Cronin J.J., Brady M.K., Hult G.T.M. (2000). Assessing the effects of quality, value, and customer satisfaction on consumer behavioral intentions in service environments. Journal of Retailing 76(2), 193-218. DOI: 10.1016/S00224359(00)00028-2

22. HeY., Song H. (2009). A mediation model of tourists' repurchase intentions for packaged tour services. Journal of Travel Research 47(3), 317-331. DOI: 10.1177/0047287508321206

23. Sheth J.N., Newman B.I., Gross B.L. (1991). Why we buy what we buy: A theory of consumption values. Journal of Business Research 22(2), 159-170. DOI: 10.1016/01482963(91)90050-8

24. Holbrook, M.B. (1999). Introduction to consumer value. Routledge.

25. Moliner M.A., Sanchez J., Rodriguez R.M., Callarisa L. (2007). Perceived relationship quality and post-purchase perceived value. European Journal of Marketing 41(11/12), 1392-1422. DOI: 10.1108/03090560710821233

26. Lee C., Yoon Y., Lee S. (2007). Investigating the relationships among perceived value, satisfaction and recommendations: The case of the Korean DMZ. Tourism Management 28(1), 204-214. DOI: 10.1016/j.tourman.2005.12.017

27. Cho M., Yang S. (2008). Information value structure for vacation travel. Journal of Travel Research 47, 72-83. DOI: 10.1177/0047287507312422

28. Gallarza M.G., Ruiz-Molina M.E., Gil-Saura I. (2016). Stretching the value-satisfaction-loyalty chain by adding value dimensions and cognitive and affective satisfactions. Management Decision 54(4), 981-1003. DOI: 10.1108/MD07-2015-0323

29. Williams P., Soutar G., Ashill N.J., Naumann E. (2017). Value drivers and adventure tourism: A comparative analysis of Japanese and Western consumers. Journal of Service Theory and Practice 27(1), 102-122. DOI: 10.1108/JSTP-07-2015-0175

30. Agarwal S., Teas R.K. (2001). Perceived value: Mediating role of perceived risk. Journal of Marketing Theory and Practice 9(4), 1-14. DOI: 10.1080/10696679.2001.11501899

31. Woodruff, R. B. (1997). Customer value: The next source for competitive advantage. Journal of the Academy of Marketing Science 25(2), 139-153. DOI: 10.1007/BF02894350

32. Zeithaml V.A. (1988). Customer perceptions of price, quality and value: A means-end model and synthesis of evidence. Journal of Marketing 52(3), 2-22. DOI: $10.1177 / 002224298805200302$

33. Hutchinson J., Lai F., Wang Y. (2009). Understanding the relationships of quality, value, equity, satisfaction, and behavioral intentions among golf travelers. Tourism Management 30(2), 298-308. DOI: 10.1016/j.tourman.2008.07.010

34. Sabiote, C.M., Frías, D.M., Castañeda, J.A. (20013). The moderating effect of culture on overall perceived value in the online purchasing process. Service Business 7, 83-102 (2013). DOI: 10.1007/sll628-012-0146-x

35. Teas R.K., Agarwal S. (2000). The effects of extrinsic product cues on consumers' perceptions of quality, sacrifice, and value. Journal of the Academy of Marketing Science 28(2), 278-291. DOI: 10.1177/0092070300282008

36. Cochran W.G. (1977). Sampling techniques (3rd ed.). Wiley.

37. DeVellis R.F. (2016). Scale development: Theory and applications (4th ed.). Sage.

38. Netemeyer R.G., Bearden W.O., Sharma S. (2003). Scaling procedures: Issues and applications. Sage.

39. Caruana A., Ewing M.T. (2010). How corporate reputation, quality, and value influence online loyalty. Journal of Business Research 63(9), 1103-1110. DOI: 10.1016/j.jbusres.2009.04.030

40. Cater T., Cater B. (2010). Product and relationship quality influence on customer commitment and loyalty in B2B manufacturing relationships. Industrial Marketing Management 39(8), 1321-1333. DOI: 10.1016/j.indmarman.2010.02.006

41. Arbuckle J.L. (2017). IBM SPSS Amos 25 user's guide. Amos Development Corporation.

42. Anderson J.C., Gerbing D.W. (1988). Structural equation modeling in practice: A review and recommended twostep approach. Psychological Bulletin 103(3), 411-423. DOI: $10.2307 / 3151719$

43. Lawshe C.H. (1975). A quantitative approach to content validity. Personnel Psychology 28(4), 563-575.

44. Hair J.F., Babin B.J., Black W.C., Anderson R.E. (2018). Multivariate data analysis (8th ed.). Pearson. 
45. Cronbach L.J. (1951). Coefficient alpha and the internal structure of tests. Psychometrika 16, 297-334. DOI: 10.1007/ BF02310555

46. Nunnally J.C., Bernstein I.H. (1994). Psychometric theory (3rd ed.). McGraw-Hill.

47. Kline R.B. (2015). Principles and practice of structural equation modeling (4th ed.). The Guilford Press.

48. Fornell C., Larcker D.F. (1981). Evaluating structural equation models with unobservable variables and measurement error. Journal of Marketing Research 18(1), 39-50. DOI: 10.1177/002224378101800104

49. DeCarlo L.T. (1997). On the meaning and use of kurtosis. Psychological Methods 2, 292-307. DOI: 10.1037/1082989X.2.3.292

50. Baron R., Kenny D. (1986). The moderator-mediator variable distinction in social psychological research: Conceptual, strategic and statistical considerations. Journal of Personality and Social Psychology 51(6), 1173-1182. DOI: 10.1037/0022-3514.51.6.1173.

51. Fairchild A., McQuillin S. (2010). Evaluating mediation and moderation effects in school psychology: A presentation of methods and review of current practice. Journal of School Psychology 8(1), 53-84. DOI: 10.1016/j.jsp.2009.09.001.

52. Barros C.P., Butler R., Correia A. (2010). The length of stay of golf tourism: A survival analysis. Tourism Management 31(1), 13-21. DOI: 10.1016/j.tourman.2009.02.010

53. Mazodier M., Merunka D. (2014). Beyond brand attitude: Individual drivers of purchase for symbolic cobranded products. Journal of Business Research 67(7), 1552-1558. DOI: 10.1016/j.jbusres.2014.01.015

Submitted: March 23, 2021

Accepted: August 10, 2021 